\title{
THE INFLUENCE OF GRAIN BOUNDARY CARBIDE DENSITY ON THE BRITTLE FRACTURE OF FERRITE PEARLITE STEELS
}

B. Mintz

The City Universitv, Northampton Square, London ECI. England.

ABSTRACT

The influence of carbide density on the charpy impact transition temperature The influe examined. Carbide density as measured optically using a linear intercept method. Because of the strong inter-relationships between grain size, carbide thickness and density, the carbide density could not be examined independently, and a

linear regression approach had to be used. Using this approach increasing the number of carbides intersected per m.m. by 20 raised the ITT by $\sim 20-30$ Generally the influence of carbide density on ITT is small compared with carbide thickness and grain size. Nevertheless, it is significant and probably accounts for the rather poorer than expected impact perfornance exhibited by some $\mathrm{Nb}$ and $\mathrm{Ti}$ containing steels. Nb and $\mathrm{Ti}$ seen tocy encourage carbide precipitation at the boundaries giving a tendency for both coarser carbides and a greater carbide density. Grain boundary carbides may also assist propagation of cracks present be separated from the influence of carbid

KEYWORDS

Grain boundary carbides, brittle fracture, stee 1.

INTRODUCTION

Recent work (1) on ferrite/pearlite and pearlite free steels has indicated that the criterion for brittle fracture in a charpy test can be both grain size and grain boundary carbide thickness controlled. Of the two, grain size seems to have a dominant effect but at a constant grain size, chion in carbide thickness can result in a 60 C rise in the ince temperature (ITT). The results from this work are summarised in Fig. where they have been compared with the predictions given by the Almond, Timbres and Embury model (2), for various average carbide tespectively. A curves $\mathrm{AB}, \mathrm{AC}, \mathrm{AD}, \mathrm{AE}$ and $\mathrm{AF}$ for $0, .15, .5$, 1 and further fracture criterion based on the stress needed to propagate a penny 


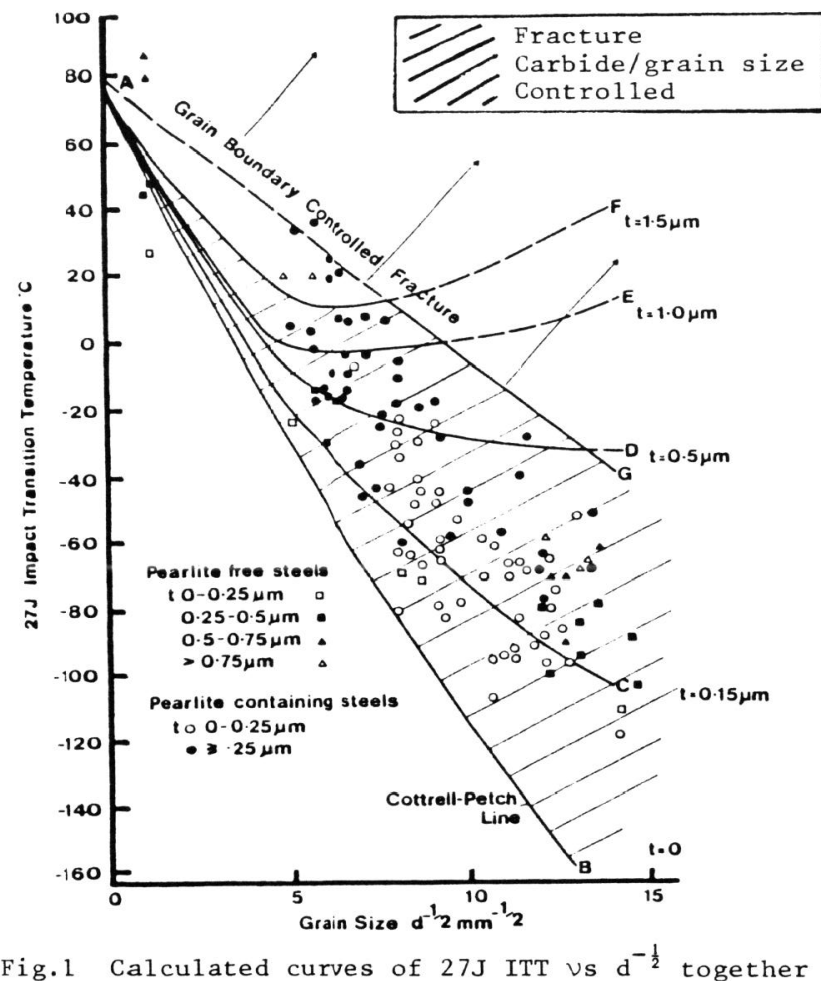
Fig.l Calculated curves of $27 \mathrm{~J}$ ITT $v$ s $\mathrm{d}^{-\frac{1}{2}}$ together
with experimental data points, after (1).

shaped crack equal in size to the grain diameter was also included in the analysis and generally defines the upper limit for ITT (curve AG). This second criteria arose because it was observed that at constant grain size size increasing the carbide thickness beyond a certain value produced no fracture process must be changing from mixed carbide/grain size controlled fracture process must be changing from mixed carbide/grain size controlled to grain boundary controlled, the ent across the boundary.

Although agreement between theory and practical results was reasonable for grain sizes $\leqslant 40 \mathrm{\mu m}$, this was not so at very coarse grain sizes (see Fig. 1 ). At a grain size of $\mathrm{d}^{-\frac{1}{2}}$ of $1 \mathrm{~mm}^{-\frac{1}{2}}$ where $d$ is the mean linear intercept grain diameter, the Almond et al model predicted that changes in carbide thickness was observed. This would suggest, whereas experimentally a change of to fracture was not as great as given by the Almond et al model.

The experimental work also suggested that at these coarse grain sizes when the carbides are coarse, the critical event in the fracture process may be the ability to propagate a crack across the boundary. (See Fig. 1)
As the grain boundary carbides ( $g b c$ ) have been shown to be important in dictating the ITT, it is felt that at a given thickness the more carbides present the greater would be the statistical probability of propagating a crack from a carbide. It would therefore be expected that the greater the density of the carbides the higher should be the ITI. In order to investigate this possibility the density of carbides has been obtained for most of the steels previously examined Ref. $(3,4)$, and compared to their respective ITT's.

\section{EXPERIMENTAL}

The steels examined consisted of a variety of structural steels having The steels examined consisted of a varietection of micro-alloying additions viz. Al, Nb, V and Ti had been added singly or in combination. In addition the following series of very low C steels (<.06\%C) were examined.

1. a commercial $13 \% \mathrm{Cr}$ ferritic stainless steel having a very coarse a commercial $13 \%$ Cr ferriti
grain size of $1-1.2 \mathrm{~mm}^{-\frac{1}{2}}$.

2. laboratory cast and hot rolled C-Mn steels having a grain size range of $5-6 \mathrm{~mm}^{-\frac{1}{2}}$,

3. fine grained

$$
\text { fine grained }
$$

A range of average grain boundary carbide thickness was achieved for these steels by different heat treatments. Full details of the composition and impact and tensile properties of the steels, their grain size and carbide thickness measurement can be found in the references $3 \& 4$. Samples for microstructure examination were etched in picral for all steels except the stainless steel where a 50/50 mixture of $5 \mathrm{~g}$ of picral acid and $5 \mathrm{ml}$ HCL per $100 \mathrm{ml}$ methanol was used in order to highlight grain boundary carbides. Although the optical microscope cannot be used to resolve the thickness of gbc, with oil immersion their presence can be clearly revealed. A linear traverse was carried out over $5 \mathrm{~mm}$ for the low alloy and C-Mn steels and $50 \mathrm{~mm}$ for the stainless steel and the number of carbides intercepted per given length is the gbc density. The carbides intersected at the boundarie where either at the tails of pearlite colonies or isolated carbides. Gbc delineating the pearlite colonies and which were generally finer were not counted.

Two parameters were chosen to relate to the ITT, $\mathrm{N}$ - the number of carbides per $\mathrm{mm}$ and $\mathrm{Nd}^{*} \mathrm{1}$ - the probability of finding a carbide at a grain boundary.

\section{RESULT}

\section{Pearlite Containing Steels}

The curves of number of carbides per $\mathrm{mm}$ (N) against grain size are given in Fig. 2. It can be seen that as the grain size becomes finer the number of carbides intersected increases. However, the steels clearly fall into two groups. At the same grain size, $\mathrm{Ti}$ and $\mathrm{Nb}$ containing steels have a greater carbide density than the plain C-Mn, the C-Mn-Al and the C-Mn-V steels. Insufficient data is available to be able to group the $\mathrm{C}-\mathrm{Mn}-\mathrm{V}-\mathrm{Nb}$ steels.

${ }^{1}{ }^{*}$ is the adjusted mean linear intercept allowing for the pearlite. 


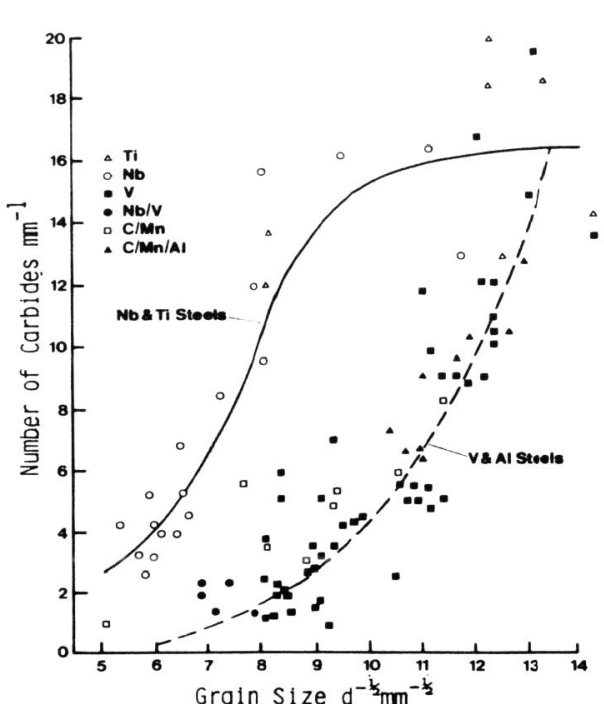

Grain Size $\mathrm{d}^{-\frac{10}{2}} \mathrm{~mm}^{-\frac{1}{2}}$

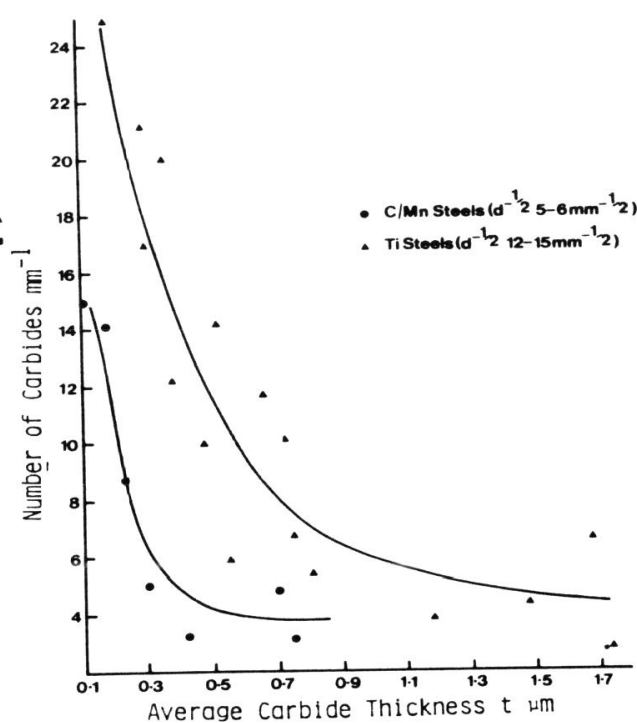

Fig. 3

\section{Pearlite Free Stee1s}

The curves of carbide density against average carbide thickness for the C-Mn, $\mathrm{Ti}$ - containing steels, and ferritic stainless steels are given in Fig. 3. The very coarse gain size of the ferritic stainless steel determined that the carbide density could only be very low. The finer grained $\mathrm{Ti}$ steels can b this is a consequence of the finer grain size or the Titanium additions. The general trend as can be seen from Fig. 3 for the 1 ow C-Mn and titanium containing steel is for seen from density decreases. In comparison the ferritic stainless steel gave the opposite behaviour, although changes were very small.

\section{DISCUSSION}

With this type of work it is very difficult to alter one variable independently of the other. Thus it can be seen from Figs. 2 and 3 that altering the carbide density generally results in either a change in the carbide thickness or a change in grain size. The difficulty in keeping the grain size and carbide thickness constant whilst altering the carbide density means that a linear regression approach has had to be taken in an attempt to
isolate the individual effects.

Previous work (3) on the pearlite containing steels has given the following linear regression equation for the $27 \mathrm{~J}$ ITT:

$$
\text { 27J ITT, }{ }^{0} \mathrm{C}=173 \mathrm{t}^{\frac{1}{2}}-8.3 \mathrm{~d}^{-\frac{1}{2}}+0.37 \Delta \mathrm{y}-42
$$

here $t$ is the average carbide thickness, $\mu \mathrm{m}, \mathrm{d}$ is the grain diameter $\mathrm{Nmm}^{-2}$, wh $\Delta y, N_{m}-2$ averathen contribution.

Strictly this equation can only be used for the conditions under which it was derived, it is reat to calculate the a obtain changes in ITT. The approach in this work has been to calculate the 27 J ITT using equation (1) for the steels examined and to subtract these 27J plotted against this difference to ascertain whether the density has any influence on ITT.

As has been mentioned, at constant grain size there is an upper limit to the Abc thickness above which it has no further effect on ITT. This limiting value has been shown to be dependent on grain size, the finer the grain siz the lower its value. However, as can be seen from Fig.4, which has been taken from previous work, (Ref. 3), it also appears as if there is a lower limit of gbc thickness. The region in which the $t^{2}$ relationship in equation purpose of this work between the limits $.25 \mu \mathrm{m}<t^{\frac{1}{2}}<0.80 \mu \mathrm{m}$.

The curves of carbide density (N) and the probability of finding a gbc carbide at the boundary $\left(\mathrm{Nd}^{*}\right)$ against the difference in $27 \mathrm{~J}$ IIT between the observed and calculated values are given in Figs. 5 and 6 for the pear containing steels respectively and Figs. 7 and 8 for the pearlite iree steels. Although there is considerable scatter it is clear that increasing $\mathrm{N}$ or $\mathrm{Nd}^{\star}$ results in an increase in $11 T$. An increase in $\mathrm{N}$. 20 to 30 C rise in the ITT for both pearlite steels. The co-relation coefficients $(r)$ for the data in figs. the pearlite containing steels which and 0.38 respectively. Much better co very different compositions were relation coefficients were and $8,0.78$ and 0.84 respectively. distribution by heat treatment alone.

A feature of the work on the pearlite containing steels at the $1 \%$ Mn A feature of the work on $\mathrm{Ti}$ and $\mathrm{Nb}$ contailevel (Rin ning steels che on average $20^{\circ} \mathrm{C}$ higher than and expects in Fig.5 and it would seem likely that points from thes are probably due to their higher gbc density (15 carbides per mm compared to 5 carbides per $\mathrm{mm}$ ). It should be noted that as well as having higher gbc density these steels also exhibit thicker gbc's (Ref.3). It is reasonable that $\mathrm{Nb}$ and $\mathrm{Ti}$ actively encourage both precipitation of gbc as well as their growth.

of the two factors - gbc thickness and gbc density, the effect of carbic thickness on ITT would appear to be dominant. Whereas an increase in carbide thickness can produce a $60^{\circ} \mathrm{C}$ rise in ITT, Fig. 4, increasing carb ITT, for both pearlite free and pearlite containing steels. 


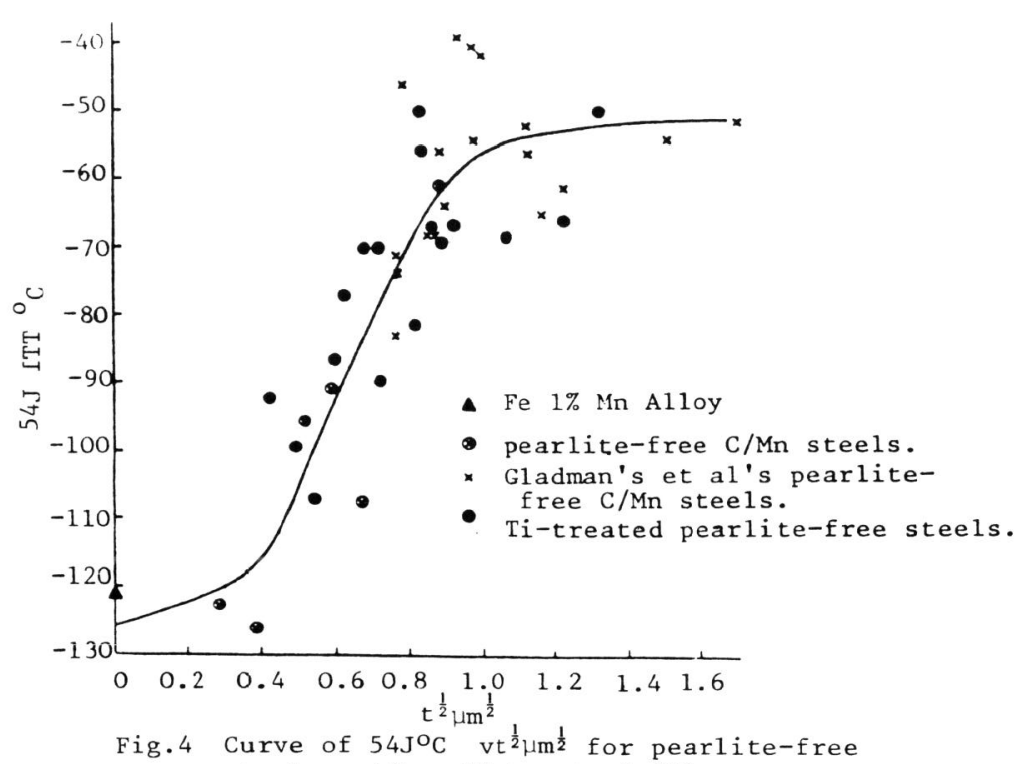
steels. After Mintz et al (3)

Influence of $\mathrm{Nd}^{*}$ on the ITT of Pearlite Containing and Pearlite Free Steels The probability of finding a carbide at a grain boundary $\mathrm{Nd} *$ can be high, and up to 1 in 2 has been recorded for the ferritic stainless steel. For of finding a carbide at a grain

As with $\mathrm{N}$ increasing $\mathrm{Nd}^{*}$ also increases the ITT (Figs. 6 and 8 ). It is not however possible to separate the individual influence of the $\mathrm{N}$ and $\mathrm{Nd}^{*}$ parameters on ITT. Although the effect of increasing carbide density on of finding a r a d a quantity Nd* (note also the effect of grain size on ITT will already have been taken account of in the regression equation as $d^{-\frac{1}{2}}$ ) might only be expected to be important if it influences the ability of a crack to beross a grain boundary. It could be imagined that if a carbide cracks and the crack propagates to the other side of the grain, its propagation over the boundary into the next grain will be e日sier if there is another brittle or low energy adhesion gbc situated at this grain boundary directly in front of the crack path. Grain boundaries are likely to be obstacles to crack propagation only when the carbides are relatively coarse which is not generally the case in the steels examined. The importance of the term $\mathrm{Nd}$ may be a consequence of the Charpy test itself where an energy criterion is used rather than a fracture stress criterion, and part of the energy recorded is related to the crack propagating through the sample.

Although it can be inferred from this work that both carbide thickness and density are significant factors in determing the ITT, metallographic

examination on broken Charpy samples to confirm these observations has
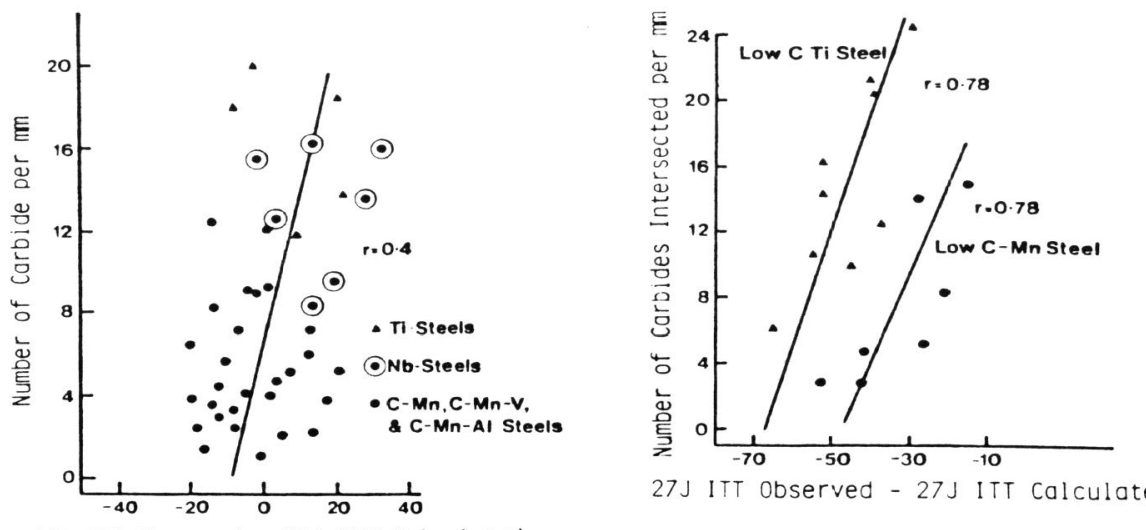

27J ITT Observed - 27J ITT Calculated

Fig. 5
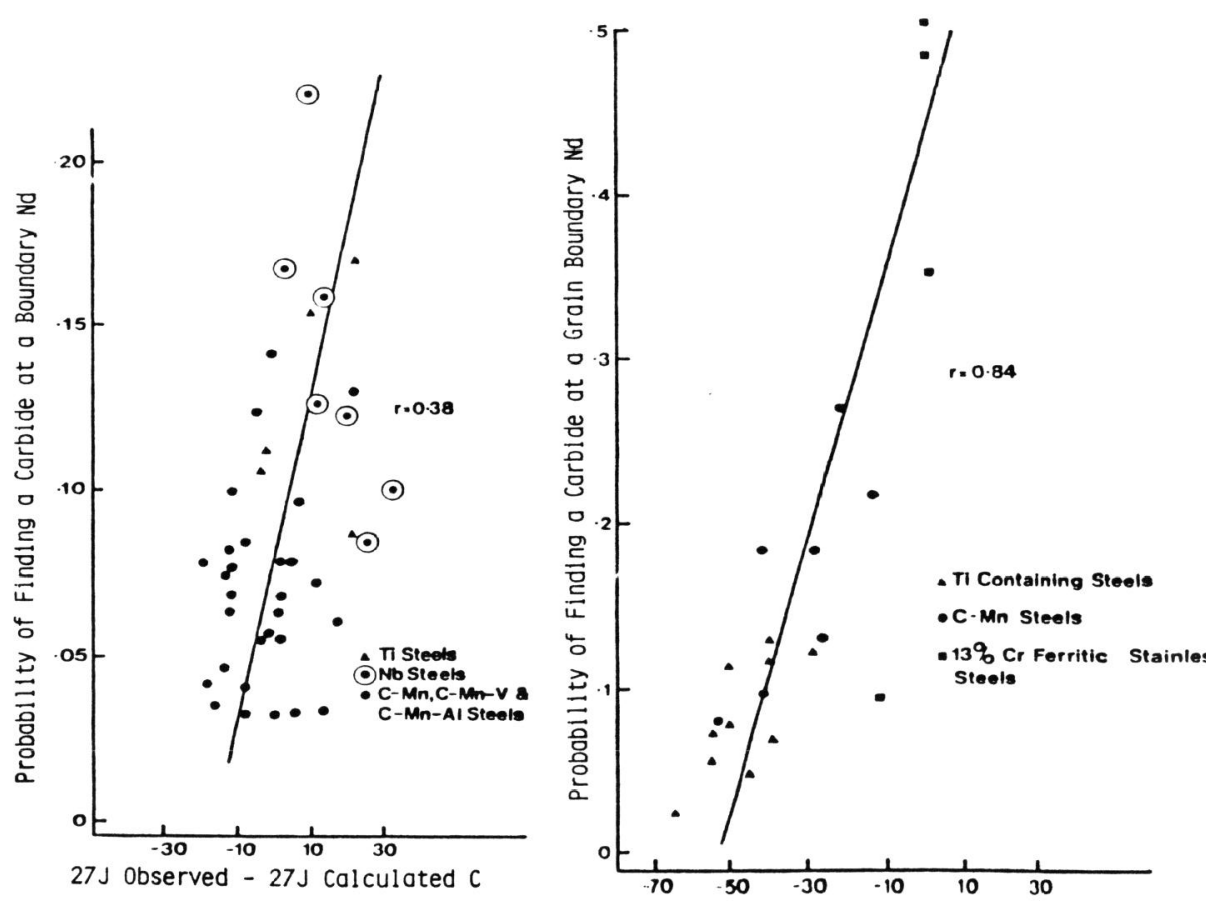

Fig. 6
27J Observed - 27J colculated C

Fig. 8 
proved difficult. Many examples of cracks going through carbide particles can be found, e.g. Fig.9, but rarely can their source be unambiguously traced to the carbide particles. This is an area for further work.

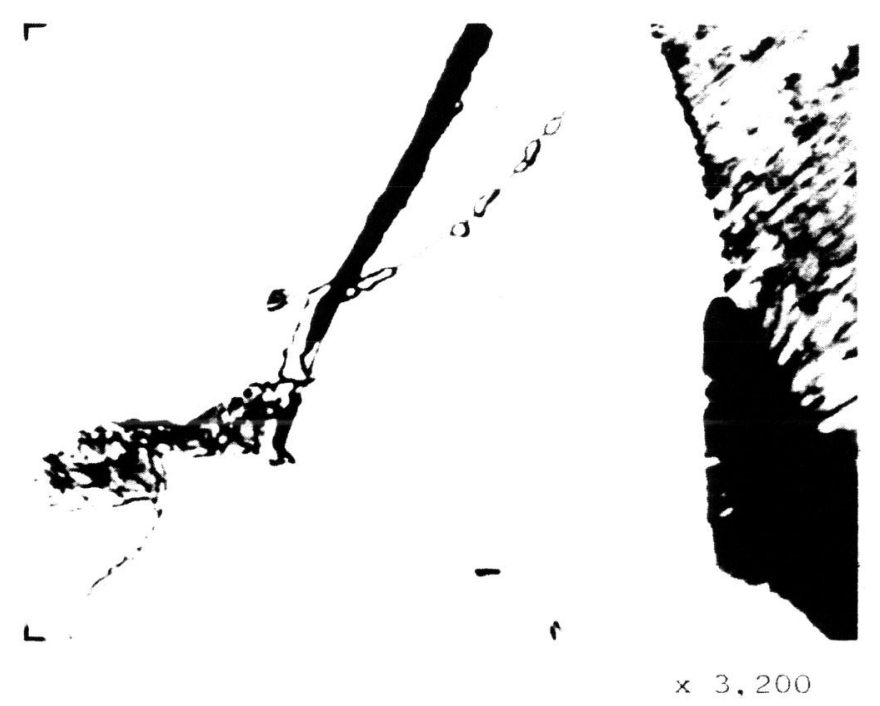

Fig.9 Example of a microcrack associated with a grain boundary carbide.

REFERENCES 1. Mintz, B., W.B. Morrison, and R.C. Cochrane. Proc. Of Conf. on Advances Sept. 1981, Metals Soc. Book 284 1982, p. 22.

. Almond, E.A., D.H. Timbres, and J.D. Embury. Conf. on "Fracture".

Vo1.6, 21, 1969, London. Academic Press.

3. Mintz, B., W.B. Morrison, and A. Jones. Met. Techno1, 1979, 6, July, 252

4. Mintz, B. and J.M. Arrowsmith. "Toughness of Ferritic Stainless Steels", STP-706, 313, 1980, ASTM, Publin.

\section{ACKNOWLEDGEMENT}

The author would like to thank the British Steel Corporation for permission to publish. The author would also like to thank Mr. R. Vipond and Dr. W.B. Morrison for their interest in the work. 